\title{
COMMENTARY
}

\section{The obesity paradox and acute kidney injury: beneficial effects of hyper-inflammation?}

\author{
Sebastian Hafner ${ }^{1}$, Andreas Hillenbrand ${ }^{2}$, Uwe Knippschild ${ }^{2}$ and Peter Radermacher ${ }^{1^{*}}$ \\ See related research by Sleeman et al., http://ccforum.com/content/17/5/R262
}

\begin{abstract}
In the general population, obesity is associated with an increased mortality risk, whereas several epidemiological studies demonstrated a protective effect of obesity in critically ill patients. In this context, Sleeman and colleagues investigated the effects of obesity on kidney function in a well-established porcine model of cardiopulmonary bypass. The authors confirm literature data that obesity per se is associated with a chronic hyper-inflammatory status. Nevertheless, obese swine undergoing the surgical procedure presented with attenuated kidney dysfunction and tissue apoptosis. The authors suggest that the chronic inflammation causes pre-conditioning against excessive acute hyper-inflammation. The authors have to be commended for using a long-term, clinically relevant model that, moreover, addresses a variety of putative mechanisms. The study is discussed in the context of the controversial findings that, in contrast to the existing literature on improved survival, most studies available suggest a higher incidence and severity of acute kidney injury in obese patients when compared with lean controls.
\end{abstract}

In a recent issue of Critical Care, Sleeman and colleagues [1] reported on the effects of obesity on kidney inflammation and function in swine undergoing cardiopulmonary bypass ( $\mathrm{CPB}$ ). Animals received a lipid-rich diet over the 12 weeks prior to surgery, resulting in 10-fold higher cholesteremia values and a $20 \%$ higher body weight. The main findings were that (i) CPB per se impaired kidney function, and (ii) pre-existing obesity attenuated kidney dysfunction on the day after the intervention. This organ-protective

\footnotetext{
* Correspondence: peter.radermacher@uni-ulm.de

'Sektion Anästhesiologische Pathophysiologie und Verfahrensentwicklung, Klinik für Anästhesiologie, Universitätsklinikum, Helmholtzstrasse 8-1, 89081, Ulm, Germany

Full list of author information is available at the end of the article
}

property of pre-operative obesity coincided with (iii) improved post-CPB renal arterial vasodilatory response to acetylcholine stimulation, (iv) better preservation of tissue nucleotide concentrations, and (v) attenuation of apoptosis. Interestingly, obesity per se was associated with an increased tissue expression of both endothelin and the inducible isoform of the nitric oxide synthase (iNOS). However, the CPB-related increase in endothelin and iNOS expression in lean swine was attenuated in obese animals. The authors conclude that the obesity-related pre-existing inflammation had 'pre-conditioning' effects against ischemia/reperfusion (I/R) injury, which may explain the 'obesity paradox' observed both in unselected ICU populations [2,3] and after cardiac surgery [4].

What is the 'obesity paradox'? In contrast to the decreased life expectancy in the general population, overweight and obesity are associated with a reduced risk of ICU death. Nevertheless, this concept is still a matter of debate, owing in large part to methodological limitations of the existing data. When baseline characteristics and therapeutic interventions were corrected for, no association between obesity and improved outcome was present in patients with septic shock [5]. After blunt trauma, higher body mass was associated with increased morbidity [6]. The relationship between obesity and acute kidney injury (AKI) is particularly intriguing: obesity per se not only is a risk factor of chronic kidney disease but also was directly related to the frequency and severity of AKI in surgical $[7,8]$ and ICU [9] populations. Finally, equivocal data are available on the effect of obesity on the inflammatory response: both depressed and aggravated cytokine profiles were reported after trauma [10] and during sepsis [11], respectively.

What do we learn from the study by Sleeman and colleagues? First of all, although some interventions may not represent current clinical standards (for example, maintaining anesthesia with halothane and nitrous oxide or high tidal ventilation using very short inspiration times), the authors have to be commended for using a 
long-term, clinically relevant large-animal model. Furthermore, various sophisticated analytical methods allowed mechanistic issues to be addressed. Nevertheless, several issues remain open. Clearly, beneficial effects of pre-procedural hyper-inflammation may be outweighed by an excess hyper-inflammatory response during circulatory depression; Duburcq and colleagues [12] reported that endotoxin caused a more pronounced cardio-circulatory depression in obese swine than in lean controls, and this depression coincided with more severe lactic acidosis, coagulopathy, and twofold proinflammatory cytokine blood levels. Furthermore, the present data on kidney function are intriguing; high fatfed animals presented with a 50\% higher creatinine clearance on the day after $\mathrm{CPB}$, whereas plasma creatinine levels did not differ. It is well established that creatinine clearance and plasma creatinine may show only a poor correlation in swine, since in this species some basal tubular creatinine secretion is present. However, the authors also report that, on the day after, CPB urinary concentrations of the neutrophil gelatinase-associated lipocalin (NGAL) did not differ between obese and lean animals. Immediately after $\mathrm{CPB}$, obese swine even showed significantly higher urinary NGAL concentrations. Sleeman and colleagues refer to NGAL as a marker of inflammation rather than glomerular or tubular damage (or both), but other authors showed that NGAL mirrors AKI in swine [13]. This issue cannot be further elucidated; unfortunately, data on kidney histology or NGAL immunohistochemistry are unavailable. Another striking finding is that the obese swine required nearly threefold higher peri-operative vasopressor doses to maintain target values for mean blood pressure; it remains open whether this is due to the reduced tissue endothelin concentration, since the lower iNOS expression in the obese animals would have suggested the opposite effect. Finally, it must be emphasized that the authors investigated young female Large-WhiteLandrace crossbred pigs that had undergone 3 months of high-fat feeding (in other words, 'obese adolescents' that mostly likely had not developed long-term consequences of obesity and hypercholesteremia). Adult minipigs of the same size can more closely mirror the typical patient undergoing cardiac surgery; prolonged feeding with a similar diet not only causes comparable hypercholesteremia but also is associated with other characteristics of the 'metabolic syndrome' (that is, arterial hypertension and impaired glucose utilization, ultimately leading to ubiquitous atherosclerosis) [13]. Moreover, similar to patients with vascular disease, this swine strain shows increased oxidative stress and reduced endogenous nitric oxide (NO) production [13]. Under these conditions, obesity-related hyper-inflammation might even cause aggravated organ injury response rather than beneficial pre-conditioning against stress conditions.
Regardless of the role of obesity for morbidity and mortality, which mechanisms are responsible for the authors' findings? Sleeman and colleagues analyzed a variety of possible players involved in obesity and inflammation: the endothelial and inducible isoforms of the NO synthase, endothelin, the nuclear transcription factor-kappa-B, and the hypoxia-inducible factor 1 alpha. However, data on changes in adiponectin concentrations are not reported. In morbidly obese subjects and patients with sepsis, the fall in adiponectin plasma levels and cytokine profiles were similar [14], and pro-inflammatory cytokine concentrations were inversely related to adiponectin concentrations in infants after cardiac surgery [15]. Intracoronary adiponectin injection attenuated organ damage during porcine myocardial I/R injury [16]. Nevertheless, controversial data are available on the role of adiponectin during AKI; both protective [17] and deleterious [18] effects during kidney I/R injury were reported. Consequently, assessment of overall or high-molecular-weight adiponectin expression (or both) would certainly have added interesting information to the study.

In conclusion, Sleeman and colleagues provide an interesting hypothesis on possible mechanisms of the obesity paradox. As is often the case with such experiments, the results raise more questions than they answer.

\section{Abbreviations}

AKI: Acute kidney injury; CPB: Cardiopulmonary bypass; iNOS: Inducible nitric oxide synthase; I/R: Ischemia/reperfusion; NGAL: Neutrophil gelatinase-associated lipocalin; NO: Nitric oxide.

\section{Competing interests}

The authors declare that they have no competing interests.

\section{Acknowledgments}

PR was supported by the Deutsche Forschungsgemeinschaft (Klinische Forschergruppe 200 'Die Entzündungsantwort nach Muskulo-Skeletalem Trauma').

\section{Author details}

${ }^{1}$ Sektion Anästhesiologische Pathophysiologie und Verfahrensentwicklung, Klinik für Anästhesiologie, Universitätsklinikum, Helmholtzstrasse 8-1, 89081, Ulm, Germany. ${ }^{2}$ Klinik für Allgemein- und Viszeralchirurgie, Universitätsklinikum, Albert-Einstein-Allee 23, 89081, Ulm, Germany.

Published: 10 Dec 2013

\section{References}

1. Sleeman P, Patel NN, Lin H, Walkden GJ, Ray P, Welsh Gl, Satchell SC, Murphy GJ: High fat feeding promotes obesity and renal inflammation and protects against post cardiopulmonary bypass acute kidney injury in swine. Crit Care 2013, 17:R262.

2. Pickkers P, de Keizer N, Dusseljee J, Weerheijm D, van der Hoeven JG, Peek $\mathrm{N}$ : Body mass index is associated with hospital mortality in critically ill patients: an observational cohort study. Crit Care Med 2013, 41:1878-1883.

3. Wacharasint $\mathrm{P}$, Boyd JH, Russell JA, Walley KR: One size does not fit all in severe infection: obesity alters outcome, susceptibility, treatment, and inflammatory response. Crit Care 2013, 17:R122.

4. Stamou SC, Nussbaum M, Stiegel RM, Reames MK, Skipper ER, Robicsek F, Lobdell KW: Effect of body mass index on outcomes after cardiac surgery: is there an obesity paradox? Ann Thorac Surg 2011, 91:42-47. 
5. Arabi YM, Dara SI, Tamim HM, Rishu AH, Bouchama A, Khedr MK, Feinstein D, Parrillo JE, Wood KE, Keenan SP, Zanotti S, Martinka G, Kumar A, Kumar A, The Cooperative Antimicrobial Therapy of Septic Shock (CATSS) Database Research Group: Clinical characteristics, sepsis interventions and outcomes in the obese patients with septic shock: an international multicenter cohort study. Crit Care 2013, 17:R72

6. Winfield RD, Delano MJ, Dixon DJ, Schierding WS, Cendan JC, Lottenberg L, Lopez MC, Baker HV, Cobb JP, Moldawer LL, Maier RV, Cuschieri J: Differences in outcome between obese and nonobese patients following severe blunt trauma are not consistent with an early inflammatory genomic response. Crit Care Med 2010, 38:51-58

7. Kelz RR, Reinke CE, Zubizarreta JR, Wang M, Saynisch P, Even-Shoshan O, Reese PP, Fleisher LA, Silber JH: Acute kidney injury, renal function, and the elderly obese surgical patient: a matched case-control study. Ann Surg 2013, 258:359-363.

8. Curiel-Balsera EC, Munoz-Bono J, Delgado-Amaya MJ, Hinojosa-Pérez R, Reina-Toral A, Gordillo-Brenes A, Rivera-Fernández R: Consequences of obesity in outcomes after cardiac surgery: analysis of the ARIAM registry. Crit Care 2013, 17:233.

9. Soto GJ, Frank AJ, Christiani DC, Gong MN: Body mass index and acute kidney injury in the acute respiratory distress syndrome. Crit Care Med 2012, 40:2601-2608.

10. Winfield RD, Delano MJ, Cuenca AG, Cendan JC, Lottenberg L, Efron PA, Maier RV, Remick DG, Moldawer LL, Cuschieri J: Obese patients show a depressed cytokine profile following severe blunt trauma. Shock 2012, 37:253-256.

11. Simon P, Thomas-Rüdde D, Nemes T, Reinhart K, Bloos F, Kaisers UX: Obesity and inflammatory markers in severe sepsis. Crit Care 2013, 17:S10.

12. Duburcq T, Hubert T, Mangalaboyi J, Saint-Léger P, Gmyr V, Qintanae L, Tounoys A, Tailleux A, Pattou F, Jourdain M: Obesity impairs organ function in a porcine model of endotoxic shock. Réanimation. in press.

13. Matějková Š, Scheuerle A, Wagner F, McCook O, Matallo J, Gröger M, Seifritz A, Stahl B, Vcelar B, Calzia E, Georgieff M, Möller P, Schelzig H, Radermacher P, Simon F: Carbamylated erythropoietin-FC fusion protein and recombinant human erythropoietin during porcine kidney ischemia/reperfusion injury. Intensive Care Med 2013, 39:497-510.

14. Hillenbrand A, Knippschild U, Weiss M, Schrezenmeier H, Henne-Bruns $D_{1}$ Huber-Lang M, Wolf AM: Sepsis induced changes of adipokines and cytokines - septic patients compared to morbidly obese patients. BMC Surg 2010, 10:26.

15. Cao Y, Yang T, Yu S, Sun G, Gu C, Yi D: Relationships of adiponectin with markers of systemic inflammation and insulin resistance in infants undergoing open cardiac surgery. Mediators Inflamm 2013, 2013:187940.

16. Kondo K, Shibata R, Unno K, Shimano M, Ishii M, Kito T, Shintani S, Walsh K Ouchi N, Murohara T: Impact of a single intracoronary administration of adiponectin on myocardial ischemia/reperfusion injury in a pig model. Circ Cardiovasc Interv 2010, 3:166-173.

17. Cheng CF, Lian WS, Chen SH, Lai PF, Li HF, Lan YF, Cheng WT, Lin H: Protective effects of adiponectin against renal ischemia-reperfusion injury via prostacyclin-PPARa-heme oxygenase-1 signaling pathway. J Cell Physiol 2012, 227:239-249.

18. Jin X, Chen J, Hu Z, Chan L, Wang Y: Genetic deficiency of adiponectin protects against acute kidney injury. Kidney Int 2013, 83:604-614.

\section{$10.1186 / \mathrm{cc} 13152$}

Cite this article as: Hafner et al:: The obesity paradox and acute kidney injury: beneficial effects of hyper-inflammation?. Critical Care 2013, 17:1023 